\title{
Long-term outcome in childhood hydrocephalus: a comparison of child and parental perceptions of health outcome Abhaya V Kulkarni* and Iffat Shams
}

\author{
Address: Division of Neurosurgery, Hospital for Sick Children, 555 University Avenue, Toronto, Ontario, M5G 1X8, Canada \\ Email: Abhaya V Kulkarni* - abhaya.kulkarni@sickkids.ca \\ * Corresponding author
}

from 50th Annual Meeting of the Society for Research into Hydrocephalus and Spina Bifida

Cambridge, UK. 30 August - 2 September 2006

Published: 2I December 2006

Cerebrospinal Fluid Research 2006, 3(SuppI I):S34 doi:I0.II86/1743-8454-3-SI-S34

(c) 2006 Kulkarni and Shams; licensee BioMed Central Ltd.

\section{Background}

Assessment of outcome and quality of life in children with hydrocephalus should attempt to obtain the perspective of the children themselves, when possible. Although we have developed the Hydrocephalus Outcome Questionnaire (HOQ) for parents, the aim of this study was to assess the scientific properties of a child-completed version of the HOQ (cHOQ) and compare child and parent responses in a select group of older, higher-functioning children with hydrocephalus.

\section{Materials and methods}

All children with previously treated hydrocephalus and between 10 and 18 years old attending the neurosurgery out-patient clinic at Hospital for Sick Children (Sick Kids), Toronto were asked to participate, if their parents felt they were cognitively capable of completing the cHOQ. The parents then completed the HOQ and the Health Utilities Index, while the child completed the cHOQ. The children were also asked to complete the cHOQ again, approximately 2 weeks later. Reliability coefficients were calculated and comparisons were made between parent HOQ and child $\mathrm{CHOQ}$ responses.

\section{Results}

A total of 154 children participated (mean age 14.3 years, SD 2.4). Their mean cHOQ Overall Health score was 0.79 (on a scale of $0=$ worst outcome to $1.0=$ best outcome), SD 0.14. For the CHOQ Overall Health score, the internal consistency reliability was 0.92 and the test-retest reliabil- ity was 0.87 (95\% CI 0.79-0.92). Mother-child agreement and father-child agreement were 0.67 and 0.74 , respectively. Agreement was higher for assessments of physical health, but lower for assessments of cognitive health and social-emotional health. When there was disagreement, it seemed that children tended to rate their health better than their parents did.

\section{Conclusion}

In a select group of older children with hydrocephalus, the cHOQ appears to be a scientifically reliable means of assessing long-term outcome and quality of life. Agreement with parental responses was reasonably good for physical health, but poorer for cognitive and social-emotional health, with parents generally providing a relative underestimate of quality of life. The differences in child and parent perception of health need to be appreciated when conducting outcome studies in this population. 